\title{
The Effects of Political Talk Radio On Political Attitude Formation: Exposure Versus Knowledge
}

\author{
GANGHEONG LEE and JOSEPH N. CAPPELLA
}

\begin{abstract}
The effects of political news on the mass audience are usually difficult to establish empirically. Recent models of mass communication effects have held that political knowledge is a better indicator of media reception than traditional measures of exposure. This claim is tested in two studies of attitudes toward Democratic and Republican leaders during the 1996 U.S. presidential primary campaigns. The impact of messages from three types of political talk radio (PTR) is examined: Rush Limbaugh, other conservative hosts, and liberal/moderate hosts. Political knowledge and exposure to talk radio are found to be equally good predictors of attitudes toward political leaders when studied separately. However, when tested against one another, exposure is the more effective measure. Agreement between Rush Limbaugh's messages and his audience's attitudes toward political figures is consistent and strong. Biased processing of PTR content by audience members with partisan predispositions contrary to those of the host is also examined.
\end{abstract}

Keywords attitude formation, biased processing, media exposure, political knowledge, political leaders, political talk radio

This article examines the effects of political talk radio (PTR) on the formation of voters' attitudes toward political leaders. Political talk radio can be defined as "call-in shows that emphasize discussion of politicians, elections, and public policy issues" (Knight \& Barker, 1996, p. 2). Political talk radio was once viewed primarily as a form of entertainment, especially for the lonely (Armstrong \& Rubin, 1989; Bierig \& Dimmick, 1979; Turow, 1974) and for the less affluent and educated (Crittenden, 1971; Surlin, 1986). In recent years, however, PTR has grown as a major source of political information for many of its audience members. In some circumstances, it can also be a determinant of public opinion and political behavior (Knight \& Barker, 1996).

Researchers have tried to determine whether media exposure or political knowledge is the better measure of reception of mass communication. Political talk radio provides a good context in which to test Zaller's (1996) claims about media effects because sound

GangHeong Lee is an assistant professor at Taegu University, Korea. Joseph N. Cappella is a Professor at the Annenberg School for Communication, University of Pennsylvania. The data reported in this article were collected as part of the political talk radio project conducted at the Annenberg School for Communication and funded by grants to Kathleen Hall Jamieson and Joseph N. Cappella from The Ford Foundation and the Carnegie Corporation of New York. The views presented are those of the authors alone.

Address correspondence to GangHeong Lee via e-mail: glee @asc.upenn.edu. 
measures of media reception are available, and variance in the content of the messages sent by hosts about political leaders is large. Under these circumstances, Zaller predicts that the effects of messages will be large when receipt of those messages is properly measured.

Studies of the impact of political talk radio have focused on the nature of democratic participation (Bick, 1988; Page \& Tannenbaum, 1996), political and social alienation (Hoffstetter et al., 1994; Petrozzello, 1994), and public opinion and political behavior (Barker, 1996; Boyer, 1992; Herbst, 1995). However, there is little systematic research on the impact of political talk on attitudes toward political leaders.

Ever since publication of Joseph Klapper's (1960) seminal book, The Effects of Mass Communication, there have been attempts to solve the puzzle of "minimal effects" in mass communication research, from exploring new "strong or powerful effect" theories to reconsidering methodological weaknesses such as measurement problems and study designs. For example, McGuire (1986) developed systematic explanations to salvage the myth of media effectiveness. He proposed a number of rescue routes. Among them was improving the reliability and validity of exposure to the very media whose effects are being evaluated. The most common measure of media exposure comes from individual-level cross sectional surveys. These questions generally request a direct report from respondents about their consumption of newspapers, magazines, and the like. This procedure, however, suffers from a variety of problems including social desirability, recall errors, restricted range, and confusion between exposure and attention (see also Price \& Zaller, 1993).

According to Bartels (1993), small effect sizes in studies of media are due in large measure to errors of unreliability. Correction for these errors provides more accurate and larger effects for media exposure. Using repeated measurement of exposure and attitude at three waves during the 1980 American National Election Study (NES), Bartels obtained estimates of the magnitudes of those errors. Attention to the effects of measurement error significantly increased the apparent impact of media exposure on opinion change in a presidential campaign setting. ${ }^{1}$

Corrections for reliability do not address issues of validity. Reliable reports of exposure do not tell us anything about attention to news. Reliable reports of attention and exposure do not indicate how well the audience incorporates information into memory for later use. Once reliability is assumed, validity still looms as a measurement issue. One solution has been to target media exposure measures to specific media and specific issues. For instance, McLeod and McDonald (1985) distinguish between general media exposure and specific exposure to public affairs content in newspaper and television. They conclude that general media exposure is not an effective predictor of learning of specific content.

A second alternative is to measure both exposure and attention. Attention and exposure differ. The former taps one's motivation state when consuming the news. The latter does not ensure mental engagement of a serious nature. Recent studies advocate treating exposure and attention as distinct variables producing different results (Drew \& Weaver, 1990; Krosnick \& Brannon, 1993; Rahn, Krosnick, \& Breuning, 1994) and reveal that attention has the power to predict learning as well as or even better than exposure does (Chaffee \& Schleuder, 1986; Joslyn \& Ceccoli, 1996). Validity might be enhanced by adding attention to measures of exposure and by employing more focused content-specific questions about exposure. An alternative focuses instead on political knowledge as a measure of the reception of mass communication. 


\section{A Model of Media Effects}

One theorist has argued that capturing media effects on political attitudes requires that two conditions be met (Zaller, 1996). The first is good measurement of habitual reception of information from the mass media. The second is variance in the content of the mass communication to which individuals are exposed. Neglecting either of these basic conditions is a principal reason for finding only minimal effects.

\section{Habitual News Reception}

Zaller (1992) argues that a simple self-report of news exposure is not useful in capturing what people are "taking in" from mass media. Instead, he returns to Hovland's threestep persuasion process: exposure, reception, and yielding or accepting (Hovland, Janis, \& Kelley, 1953). Exposure to a persuasive message involves "only physical proximity to a message, as in the case of who is present in a room in which radio news is plainly audible but who is too distracted to listen" (Zaller, 1992, p. 21). Reception involves "actually 'getting' or 'cognizing' the given message" (p. 21). Zaller concludes that reception of communication should be the target of measurement because in the chain of persuasion it is closest to yielding or accepting, the indicator of successful media effects.

Zaller suggests political awareness as a measure of reception. Political awareness is indicated by simple tests of objective political knowledge (for example, the name of the speaker of the U.S. House of Representatives). Presumably, correct answers to these kinds of questions indicate reception and also are indicators of attentive exposure to media because citizens will have acquired much of their current political knowledge from the mass media.

Political knowledge as an indicator of reception of media news may have some advantages in comparison with media exposure. First, information questions do not suffer as much from inaccurate reporting as do typical media exposure measures because "a respondent cannot easily reveal information he does not possess" (Price \& Zaller, 1993, p. 139). Tests of knowledge about public affairs also are more specific than global assessments of media exposure. Tests of political knowledge automatically accommodate individual differences in learning ability and in use of different media (Price \& Zaller, 1993).

Price and Zaller (1993) tested the effects of media exposure (e.g., national and local newspaper and television exposure, and talk radio exposure) versus "general political knowledge" 2 as predictors of people's learning from news stories appearing in the national news agenda. They report that the logistic regression coefficients for the exposure measures and political discussion were small relative to those obtained for education (mean $\beta$ across 16 stories $=.76$, with an average $32 \%$ reduction in classification errors). In contrast, prior political knowledge had a much stronger relationship to learning news items (mean $\beta=1.30$ ). ${ }^{3}$ Coefficients for newspaper exposure and political discussions were, with a few exceptions, reduced to nonsignificance. National TV news exposure produced significant, although relatively small, coefficients in about half of the equations.

In sum, the results tell us that political knowledge is a strong and significant predictor of learning even controlling for education, while newspaper exposure is insignificant and television news exposure has small effects. ${ }^{4}$ Price and Czilli (1996) confirmed these results using news recognition in addition to news recall as an outcome variable. The 
use of general political knowledge as a measure of habitual news reception is a reliable and parsimonious way of capturing what people actually receive or learn from news. However, Zaller and Price's use of news recall as a measure of learning from news smacks of a conceptual, although not operational, tautology. If habitual news reception is based on current knowledge of political figures or civics knowledge and the test of the validity of this concept is its ability to predict knowledge of current affairs, then at a minimum there is shared methods variance. At the conceptual level, there is little distinction between general political knowledge and news recall in terms of habitual news reception.

The validity of civics knowledge as a measure of news reception requires other tests not involving simple knowledge as the criterion. Such tests have been reported (Cappella \& Jamieson, 1997a; Zaller, 1992, 1994, 1996; Zaller \& Hunt, 1995). Specifically, tests of the relationship between political awareness (as media reception) and attitudes toward the Vietnam War (Zaller, 1992), the Perot candidacy (Zaller \& Hunt, 1995), the Gulf War (Zaller, 1994), Clinton's health care plan (Cappella \& Jamieson, 1997a), and other outcomes have been carried out. However, to our knowledge, there have been no direct tests comparing knowledge with exposure in predicting attitude and opinion formation. We conduct just such a comparative test here.

\section{Variance in Communication Campaigns}

The second condition necessary to observe media effects is variance in key independent variables, specifically the content of the communications to which individuals are exposed. Zaller (1996) argues that the influence of political communication from mass media is systematically underestimated. If the mass media routinely "carry competing political messages, members of the public who are heavily exposed to one message tend to be heavily exposed to its opposite as well" (p. 20). Each opposing message system could cancel out the real effects of the separate messages if received alone. McGuire (1986) agrees. The two most intensely studied domains of intended mass media effects, commercial advertising and political campaigns, usually offer mutually opposing messages. The lack of net effect can be attributed to cancellation produced by messages pushing in different directions.

The mass media carry competing messages in many political environments. Much media research has neglected the effects of these message environments. If cancellation of effects is the rule and both pro and con content is received without bias by the audience, then minimal effects would result regardless of exposure levels. However, receivers are likely to vary in both reception and acceptance of competing messages. In testing the effects of a communication campaign on political opinion, researchers need to keep track of the relative intensity of information flow affiliated with each side in the campaign, and the consistency of pro and con information available to the audience. According to Zaller's model, the more intense campaign will dominate attitude change. This relative intensity of information flow depends on the discourse of political elites. For example, if coverage of the Gulf War is substantially more hawkish than dovish, the dominant trend is conservative, and political opinion should be supportive of the war.

When one side dominates, the simplest theory of media effects is that there should be a monotonic, positive relationship between general awareness and acceptance of the dominant message. Furthermore, this pattern should be sharper among those whose ideological pre-dispositions are consistent with the message. If countervailing messages become a 
part of public discourse, then those people whose predispositions are consistent with the countervailing messages and who have a high level of general political awareness will pick up the countervailing message and form their opinions accordingly. If the message is strong enough to reach those who have a moderate level of awareness, they, too, will change their positions. Those with the lowest level of awareness remain as laggards and slow to change their attitude because they get little or no political information. Even though they are persuadable, they are relatively unaffected by political messages that do not reach them.

Contrary messages inconsistent with the audience's predispositions will be resisted by the highly aware, a kind of inertial resistance. The level of attitude change in the highest knowledge group would be the same as in the lowest knowledge group. Although those with little knowledge are presumed to be easiest to change, they also have little exposure to the persuasive messages. In a model in which attitude change is the result of reception times resistance to change, the greatest change should be for the moderate knowledge group. They pay enough attention to the political messages but lack the resources to resist. We will test explicitly for these nonlinear effects.

\section{Biased Processing}

Our discussion of media effects thus far has assumed a homogeneous audience free of the forces of selective exposure, recall, and perception. However, these biases are common (Sears \& Kosterman, 1994; Sniderman, Brody, \& Tetlock, 1991) and should be taken into account in any model of political persuasion. Zaller does so in his work on attitudes toward the Gulf War (Zaller, 1994), Vietnam (Zaller, 1992), and domestic issues such as welfare, civil liberties, and racial policy (Zaller, 1992). The gist of the argument is that even in a media environment of roughly balanced coverage of an issue, people will be influenced disproportionately by arguments that are consistent with their ideological and value predispositions. They are biased processors of information, either because they attend to information that is consistent with their positions or because they find ideologically consistent arguments more persuasive. Whatever the reason, valuebased predilections within segments of the audience may result in biased processing. For example, the more knowledgeable liberal Democrats are, the more their attitudes toward the Gulf War may diverge from those of conservative Republicans (Zaller, 1994). The explanation is that arguments against war in Iraq were "getting through" to liberal Democrats (especially those higher in habitual news reception), while arguments in favor were getting through to conservative Republicans.

We assume that even in a media environment such as PTR, where a dominant ideological position prevails, those listeners holding a contrary ideology (few in number though they be) will be less likely to be influenced by the dominant message. In short, they will be biased against it, because of selective attention, recall, perception, or perhaps counterarguing. This speculation will be tested in our research.

\section{Research Goals}

Zaller's model offers an elegant, logically consistent, and potentially powerful theory of opinion change, but the aspects of the theory are difficult to verify empirically. One serious difficulty is locating real-world communication environments where one side of a political issue is dominant. Political talk radio presents a good context in which to test Zaller's model. In contrast to mainstream news media, PTR is largely partisan. 
Shows and hosts are mostly conservative, although some identify themselves as liberal or moderate. The norm is one-sidedness (Cappella, Jamieson, \& Turow, 1996). If listeners to political talk radio can be separated into (a) those who consume regularly one ideological source and (b) those who either do not consume regularly or (c) those who consume several different partisan voices, then PTR will provide a good context for testing Zaller's claims.

Our research was conducted to evaluate the association between PTR reception and attitude toward political leaders of both the Democratic and Republican parties and to compare directly knowledge measures of reception with exposure measures as predictors of attitudes toward political leaders. Our first goal takes a step toward answering questions about the influence of PTR on public opinion, particularly opinion about political leaders. The audiences of PTR are highly partisan, as is the speech of its hosts. The audience of Rush Limbaugh, for example, is very Republican and very conservative (Cappella et al., 1996). Limbaugh's rhetoric is the rhetoric of a political party leader and strong partisan. His message is anything but the norm of balance sought, if not achieved, by the mainstream media (Jamieson, Cappella, \& Turow, 1998). The consequence of audience self-selection, combined with attitudinally consistent messages from the host, raises a question. Is political talk radio merely "preaching to the choir" and reinforcing existing attitudes and opinions? Does increased exposure encourage stronger attitudes on issues discussed?

Our second goal pits two measures of reception against one another: knowledge and exposure. Although previous research has shown that prior political knowledge is a better predictor of recalling and recognizing news items than are education and simple media news exposure, we know of no comparative tests of exposure and knowledge as predictors of political attitudes. We carry out just such a comparative test in the context of PTR exposure-an environment with good communication variance.

Our third goal tests biased processing. Despite the self-selection that the audiences of PTR exhibit, some Democrats and self-identified moderates do listen to conservative hosts and some Republicans and moderates listen to liberal hosts. These biases should affect the way these subgroups process the messages the hosts offer, attenuating the relationship between news reception (knowledge or exposure) and attitude that would otherwise be observed in a more sympathetic audience.

We offer no hypotheses about the relative strength of simple media exposure and knowledge as predictors of attitudes toward political leaders. This is left as a research question. However, we do expect political talk radio and its barrage of partisan commentary about political leaders to be linearly or curvilinearly associated to attitudes toward those leaders consistent with the hosts' message.

H1: Listeners to conservative political talk radio will show more favorable attitudes toward Republican political figures as their news reception level increases, while nonlisteners will not.

H2: Listeners to conservative political talk radio will show less favorable attitudes toward Democratic political figures as their news reception level increases, while nonlisteners will not.

$H 2 a$ : Democrats and moderates who listen to conservative political talk radio will have a less negative relationship between news reception and their attitudes toward Democratic political figures than will Republican listeners.

$H 2 b$ : Democrats and moderates who listen to conservative political talk radio will have a more negative relationship between news reception and their attitudes toward Republican political figures than will Republican listeners. 
H3: Listeners to liberal political talk radio will show more favorable attitudes toward Democratic political figures as their news reception level increases, while nonlisteners will not.

H4: Listeners to liberal political talk radio will show less favorable attitudes toward Republican political figures as their news reception increases, while nonlisteners will not.

H4a: Republican and moderate listeners to liberal political talk radio will show a less negative relationship between news reception and their attitudes toward Republican political figures than will Democratic listeners.

$H 4 b$ : Republican and moderate listeners to liberal political talk radio will show a more negative relationship between news reception and their attitudes toward Democratic political figures than will Democratic listeners.

\section{Research Design}

Data to evaluate our research hypotheses came from a series of five surveys on the effects of political talk radio on political judgments during the the primary phase of the 1996 U.S. presidential campaign. The survey ran from February 21, 1996, to March 5, 1996. Sampling was designed to include an oversample of people who were regular listeners of political talk radio as well as those who were not.

Regular listeners were defined as those listening to political talk radio at least two times in an average week. Three groups of regular listeners were obtained: those listening to Rush Limbaugh only $(N=213)$, those listening regularly to some other talk radio host $(N=422)$, and those listening to more than one PTR host regularly $(N=43)$. Nonregular listeners numbered 988. Those listening to more than one host were ignored in analyses. Those regularly listening to hosts other than Rush Limbaugh were subdivided into two groups: (a) regular listeners to a conservative political talk radio program $(N=139)$ and (b) regular listeners to a liberal or moderate political talk radio program $(N=283)$. Conservative, liberal, or moderate talk radio groups were distinguished on the basis of their identification of the host's political views as conservative, liberal, or moderate (Cappella et al., p. 3). The separation of listeners and nonlisteners into groups is described in the Appendix.

In general, regular listeners to PTR are more educated and older than nonlisteners, and more are male. They also tend to be White, have higher incomes, be Republican, and be conservative. There are few demographic differences among the groups of regular listeners. However, there are clear differences among them in terms of political ideology and partisanship. Rush Limbaugh listeners are more conservative (70\%) and more likely to be Republican (61.4\%) than even the listeners of conservative PTR $(47.8 \%$ conservative and $44.8 \%$ Republican). ${ }^{6}$ Regular listeners to PTR are also consumers of mainstream newspaper and television news. Regular listeners of PTR consume more news from elite media than do nonlisteners (the exception is television news, which is watched equally by listeners and nonlisteners). The three groups of regular listeners are equivalent in reading newspapers and newsmagazines and watching television for news (including C-SPAN) (Cappella et al., 1996, p. 27). The mainstream media are relatively balanced in their treatment of political leaders, so exposure to them will at most dilute the effects of partisan PTR. The somewhat greater exposure of PTR listeners to mainstream media does not confound our design but, it could be argued, makes our hypothesis tests more conservative. 


\section{Measurement}

\section{Political Knowledge}

Survey respondents were asked a variety of questions about their knowledge of political and social issues, and political figures in the news. They were asked 11 factual questions about civics, general information on social affairs, and current information and people in the news. ${ }^{7}$

Reliability tests showed that eight knowledge items out of 11 produced the highest reliability (Cronbach's alpha $=.66$ ): two civics knowledge questions ("the percent of vote for overriding a Presidential veto" and "a majority party in the United States House of Representatives"), one news knowledge question ("Steve Forbes' tax rate"), and five personality knowledge questions. These eight items were employed as a measure of political knowledge, whereas two current knowledge items ("the number of people executed each year" and "the number of people on welfare three years in a row or more") and one news knowledge item ("the proportion of U.S. troops in Bosnia") were excluded. The eight political knowledge items were summed to yield political knowledge scores ranging from 0 to 8 . Survey respondents' mean score on the eight political knowledge questions was $4.0(S D=1.6){ }^{8}$

For the validity of political knowledge, we claim that political knowledge is an indicator of reception of political news from both the mainstream mass media and PTR. This claim is supported in several ways. First, content analyses of the mainstream mass media and PTR showed a great deal of similarity in topics treated (Cappella et al., 1996). Thus, knowledge items in the mainstream mass media are also likely to occur in PTR.

Second, our data show that the regular listeners of PTR are also heavy consumers of mainstream mass media. However, PTR regulars have the same or better knowledge levels than the general audience and equal knowledge to those who are heavy consumers of mainstream mass media news. The means of the eight political knowledge questions were 4.5 for the regular listeners of Rush Limbaugh and of the conservative talk shows and 4.4 for those of the liberal/moderate talk shows. The mean also was 4.3 for those who consume national TV news and a daily newspaper regularly (more than 3 days a week). Finally, Zaller's point in his model of message reception is that the greater a person's level of political knowledge or awareness, the more likely this person is to consume information acquired from mass media regardless of sources. Therefore, if political knowledge should be an indicator of reception of the mainstream media news, it would also be an indicator of listening to PTR.

\section{PTR Exposure}

After several filter questions, exposure to political talk radio was measured by asking "on the average, how often do you listen to political talk radio?" A scale with five alternatives was used: less than once a week, once a week, twice a week, 3 times, or more than 3 times a week. In the original PTR groupings, those listening to political talk radio two or more times per week were categorized as regular political talk radio listeners. Those listening less were categorized as nonregular listeners.

PTR exposure subsequently was recoded into four levels: "less than twice a week," "twice a week," "3 times a week," and "more than 3 times a week." Nonregular PTR listeners made up the group of "less than twice a week" for each PTR group (e.g., Rush Limbaugh, conservative, and liberal/moderate group). For example, the number of regular Rush Limbaugh listeners was 213, while the nonregular listeners numbered 
988. The total sample, when considering exposure to Rush Limbaugh PTR, was 1,201 $(988+213)$.

\section{Content of PTR}

Three content analyses of political talk radio and specifically of Rush Limbaugh (Cappella et al., 1996; Inamdar \& Cappella, 1997; Knight \& Barker, 1996) confirm what even casual listening to political talk radio suggests immediately. PTR focuses to a large extent on domestic politics and shades discussion in a partisan direction. The messages one hears on much of political talk radio are the messages of the right attacking the left and vice versa. Although PTR is not monolithic either in the topics it treats or the way it treats them, the emphasis on domestic politics and partisan persuasion is consistent across the genre.

Two studies provide a sense of the content of Rush Limbaugh and liberal/moderate and conservative PTR. One study compared the topics of mainstream news sources with those of PTR during the 1996 primary campaign (Cappella et al., 1996); the other study compared the topics discussed by Limbaugh, conservative, and liberal/moderate PTR during the summer and fall of the 1996 general election campaign (Inamdar \& Cappella, 1997). The most complete and accurate data concern Rush Limbaugh's show. These are based on computerized searches of transcripts of Limbaugh from January 1, 1996, through mid-November 1996. For Limbaugh, Bill Clinton's presidency was the top-ranked issue discussed, appearing every day of the period coded. Bob Dole was discussed on $91.5 \%$ of the days. Hillary Clinton was a topic on $88 \%$ of the days. By contrast, Newt Gingrich was an object of talk on only $52.5 \%$ of the shows.

According to the now-defunct PTR daily newsletter, Talk Daily, conservative PTR hosts focused most frequently on Bill Clinton, with Bob Dole and his campaign ranking third. On liberal/moderate PTR, the Dole campaign ranked first in discussion, with all Clinton scandals ranking second (including Hillary Clinton's role in Whitewater). On both of these kinds of outlets, Newt Gingrich was near the bottom in frequency of discussion even though during that summer he was the target of an ethics probe. Thus, in all sources, the president and his scandals were a constant object of consideration. Bob Dole and his presidential campaign were also extensively discussed, ranking just below Bill Clinton's presidency. Newt Gingrich was given less attention by all three types of sources. Interestingly, the rank order of these persons in PTR was similar to that of the mainstream television news during the summer and fall of 1996 and similar to that of a sample of The New York Times coverage during the fall.

\section{Political Attitudes}

The outcome measures were favorability toward political leaders. Favorability toward political leaders such as Bob Dole, Newt Gingrich, Bill Clinton, and Hillary Clinton, and the job approval of the president and Republican leaders in Congress, were measured. The response alternatives ranged from "mostly unfavorable" to "mostly favorable" in five steps, with "can't rate" treated as a midpoint and "don't know" missing.

\section{Results}

Multiple regressions were run to evaluate the relative importance of two indicators of message reception (political knowledge and exposure) among each political talk radio 
listening group in predicting respondents' favorability toward political leaders. In the regressions, political knowledge or PTR exposure was entered in the first step, and demographics such as education, party identification, ${ }^{9}$ age, and gender were added in the next step. Other controls that might have been used were not entered, following the parsimonious principle of regression analysis. For example, it is likely that political ideology is a factor in accounting for listeners' predispositions or self-selection effect of PTR. However, political ideology was not included in the equation because it was strongly correlated with political identification $(r=.48)$. Respondents' intelligence also might influence political knowledge. However, respondents' education should control for this potential effect of intelligence on knowledge.

Our hypotheses compare the effects of political knowledge (or exposure) on political attitude among PTR listening groups. The relative slope of knowledge or exposure on political attitude for each group is examined rather than the significance of the predictive power of political knowledge within each group. Therefore, the standardized coefficients $(\beta)$ of political knowledge or PTR exposure on political attitude among each group are reported in order to allow comparison of knowledge and exposure on favorability.

\section{Reception and Attitude}

Listeners who are exposed to ideologically conservative messages should exhibit different slopes between reception and favorability than those who are exposed to more balanced message or to ideologically liberal messages. Both of the tendencies should remain after controlling for listeners' demographics. Table 1 presents the results of the regression analyses.

The first three rows are the Democratic leaders, including an evaluation of President Clinton's job performance; the next three rows are comparable attitudes toward Republican leaders. First, notice the pattern of signs for knowledge as a predictor of attitude. Those listening to conservative PTR and to Limbaugh always are more negative toward Democratic leaders as their media reception (measured as knowledge) increases ( 6 of 6 comparisons), and most of the time they are more positive toward Republican leaders with increasing knowledge (6 of 6). These two observations are true whether or not demographics are controlled. There is only one negative sign with the attitude toward Bob Dole in the conservative PTR group when demographics are controlled. Those listening to liberal/moderate PTR show a positive relationship between media reception (measured as knowledge) and attitudes toward Democratic leaders (3 of 3 comparisons). When Republicans are the target, two of three signs are negative, with only Bob Dole being rated more positive at higher levels of political knowledge (although this effect is nonsignificant). When demographics are controlled, only Newt Gingrich has a negative sign, with Bob Dole and Republican leaders' job approval being rated more positive at higher levels of political knowledge (although these effects are nonsignificant).

The pattern of the signs is just as consistent for exposure. Listeners who are exposed to more conservative talk evaluate Democrats more negatively and Republicans more positively, while those exposed to more liberal and moderate talk show the opposite relationship (18 of 18 comparisons). The signs remain the same when demographics are controlled except for two instances. Overall, if we focus just on the sign of the media reception (measured indirectly as knowledge or directly as exposure) relationships, the ideological and partisan messages of PTR are associated with its audiences' attitudes even after controlling for other demographics, including prior partisanship. 


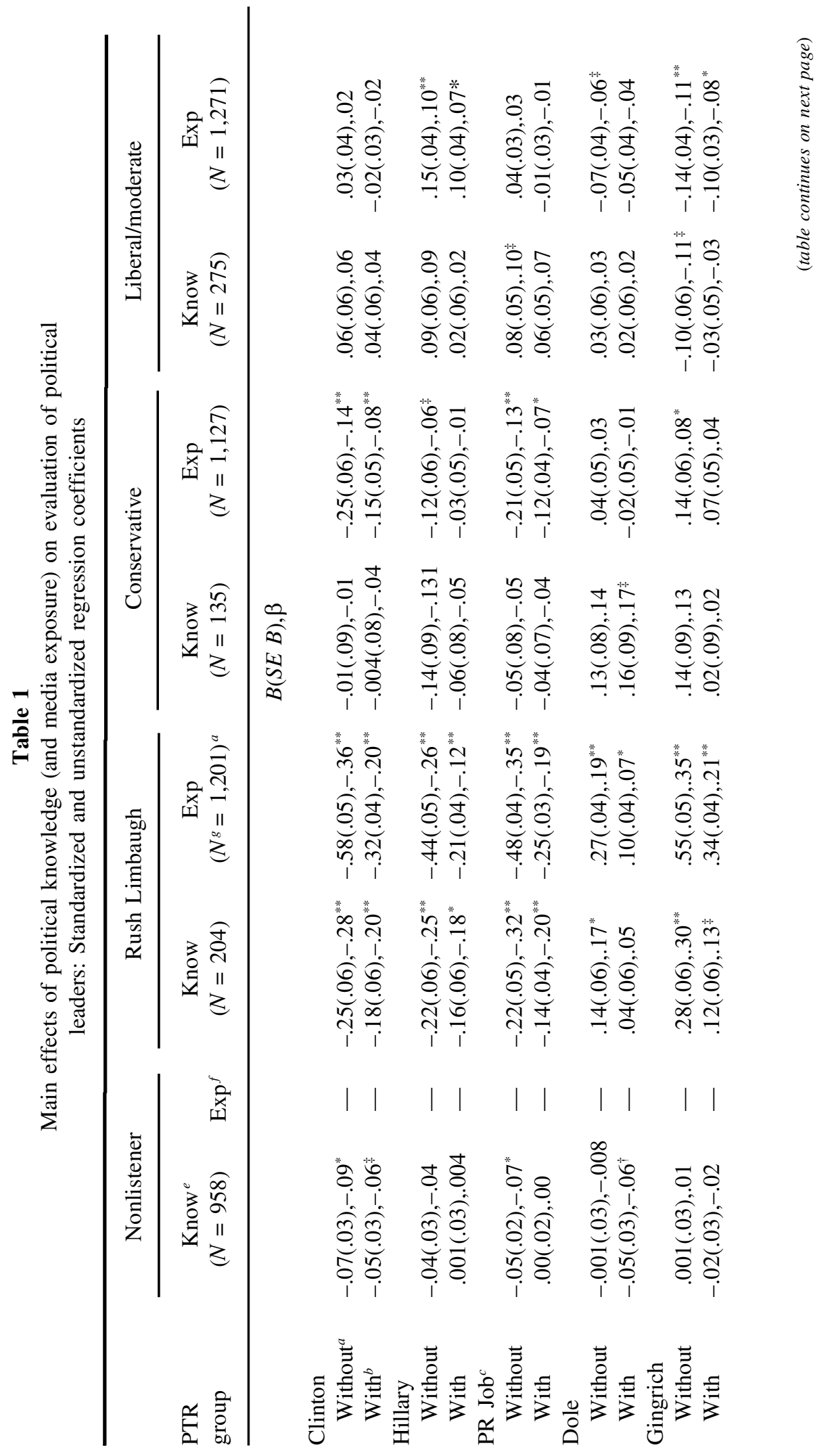




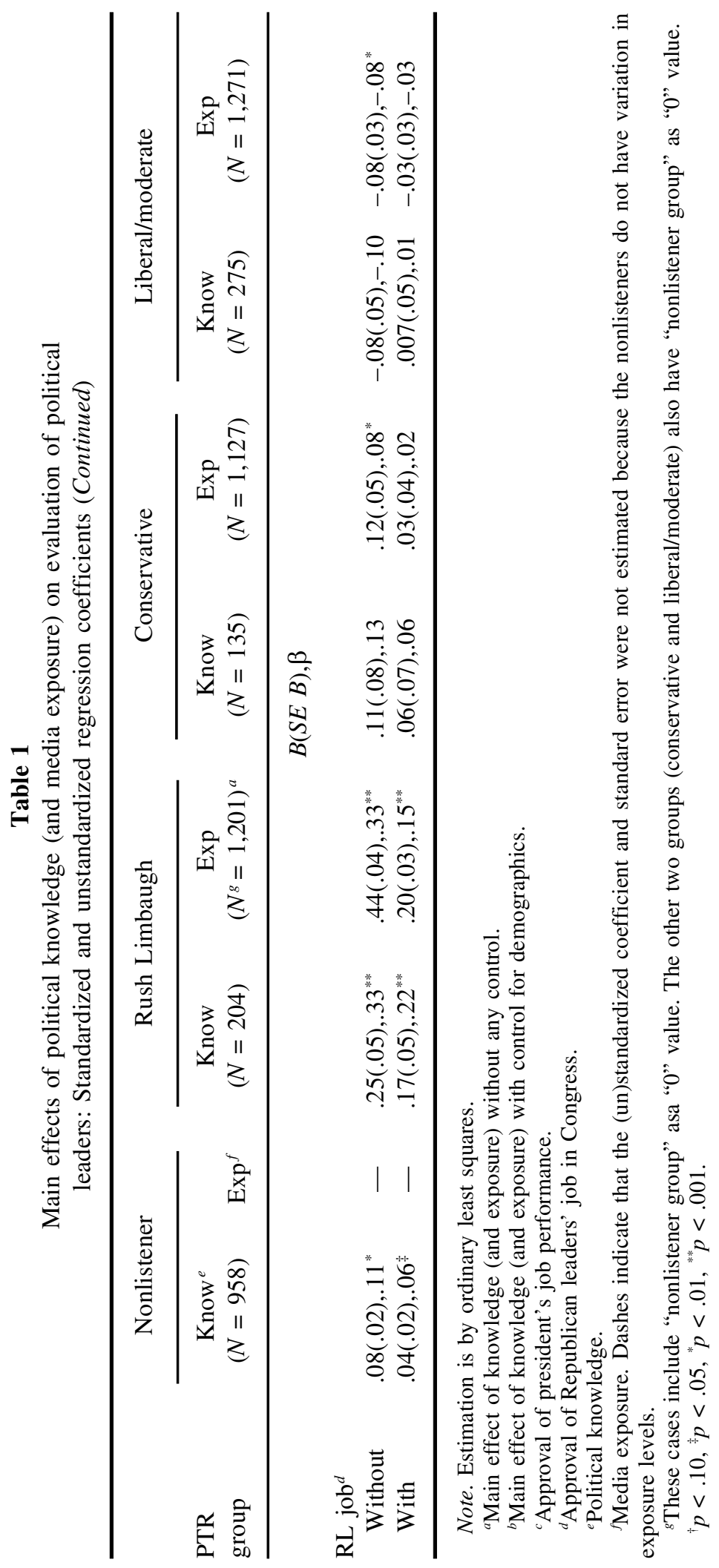


Not all of these effects are significant, of course. The strongest effects are observed among the Limbaugh audience. After controlling for demographics, knowledge is a significant predictor of attitude in 5 of 6 cases, while exposure is significant for all six outcomes. However, there are few knowledge effects among conservative and liberal/ moderate audiences. Knowledge significantly predicts only attitude toward Bob Dole among the conservative listeners. In 11 of 12 cases, knowledge fails to be a significant predictor of attitude when demographics are controlled. Exposure works better on political attitudes than political knowledge. Exposure effects are significant on attitude toward Bill Clinton and his job performance among conservative PTR listeners (2 of 6 cases) and on the attitudes toward Hillary Clinton and Newt Gingrich among the liberal/ moderate PTR audience ( 2 of 6 cases) when demographics are controlled..$^{10}$

The fact that controls for demographics reduce the impact of knowledge and exposure on political attitudes is not surprising. For example, people who are more likely to receive political messages are politically more involved with one party or the other, and they seek exposure to an ideologically consistent message (Bartels, 1993; Berelson, Lazarsfeld, \& McPhee, 1954; Zaller, 1996). Our survey of the audiences of PTR also indicates that Republicans seek more politically conservative PTR, and especially Rush Limbaugh, while Democrats select more liberal outlets. It also points out that women like Bill Clinton more than Bob Dole. Therefore, the apparent effects of media exposure or political knowledge on attitudes (before any controls) certainly reflect the impact of politically relevant characteristics that happen to be correlated with media exposure and knowledge. Some effects remain after controls for demographics are introduced.

We contend that the general effect of both political knowledge and exposure on attitudes toward leaders and job approvals does depend on the kind of content in PTR that the audience is receiving. This claim is based on the statistical analysis of the interaction between political knowledge or exposure and PTR group. This interaction was tested by examining the $R^{2}$ change in a hierarchical regression. At Step 1 the main effects, including group, knowledge (or exposure), and demographics (education, age, gender, party identification), were entered. At Step 2 the interactions between group and knowledge (or exposure) were entered. ${ }^{11}$ Results for changes in $R^{2}$ are presented in Table 2.

\section{Table 2}

Interaction effects between political knowledge (or media exposure) and PTR group on evaluation of political leaders

\begin{tabular}{lllllll}
\hline & \multicolumn{2}{c}{ Step 1 } & & \multicolumn{2}{c}{ Step 2 } \\
\cline { 2 - 5 } \cline { 5 - 6 } & Knowledge & Exposure & & Knowledge & Exposure & $N$ \\
\hline Bill Clinton & $.37\left(114.66^{* *}\right)^{a}$ & $.36\left(127.61^{* *}\right)$ & $.002(1.73)^{b}$ & $.004\left(4.65^{*}\right)$ & 1,572 \\
Hillary & $.30\left(84.32^{* *}\right)$ & $.29\left(92.81^{* *}\right)$ & $.003(1.88)$ & $.007\left(7.73^{* *}\right)$ & 1,570 \\
PR job & $.41\left(125.20^{* *}\right)$ & $.40\left(140.73^{* *}\right)$ & $.003\left(2.76^{*}\right)$ & $.003\left(4.20^{*}\right)$ & 1,477 \\
Bob Dole & $.16\left(37.31^{* *}\right)$ & $.16\left(42.49^{* *}\right)$ & $.004\left(2.19^{*}\right)$ & $.002\left(2.22^{\dagger}\right)$ & 1,543 \\
Gingrich & $.32\left(87.48^{* *}\right)$ & $.31\left(94.01^{* *}\right)$ & $.006\left(4.72^{*}\right)$ & $.013\left(14.32^{* *}\right)$ & 1,504 \\
RL job & $.43\left(129.98^{* *}\right)$ & $.42\left(142.76^{* *}\right)$ & $.004\left(2.87^{*}\right)$ & $.005\left(6.17^{*}\right)$ & 1,413 \\
\hline
\end{tabular}

${ }^{\mathrm{a}} R^{2}(F)$.

${ }^{\mathrm{b}} \Delta R^{2}(F)$.

${ }^{\dagger} p<.10,{ }^{\star} p<.05,{ }^{*} p<.01,{ }^{* *} p<.001$. 
As Table 2 suggests, the $R^{2}$ changes for political knowledge and exposure, although small, are significant for approvals and attitudes toward political figures. The exceptions are Bill Clinton with political knowledge and Bob Dole with exposure. This implies that the different slopes of the effects among the PTR groups are statistically different from one another even in the presence of additional controls. These findings also indicate that, despite the weakened effects after the control for demographics, exposure to PTRas well as political knowledge - is a good predictor of attitude toward political leaders and job approval. In fact, exposure is as strong as or stronger than political knowledge in predicting attitudes toward political leaders.

The clearest effect that emerges from the analyses in Tables 1 and 2 is that reception of political information communicated by Rush Limbaugh's show is associated with the audience's political attitudes. When Limbaugh condemns the president, as he does daily, that is linked to negative attitudes toward Bill Clinton and his job performance. When he praises the Republicans and their leadership, which he does very frequently, audiences reflect those attitudes.

The content of other conservative and liberal/moderate PTR is more difficult to ascertain because of the number of different hosts and their mixed messages. The Clinton scandals were discussed frequently by the liberal/moderate and the conservative hosts during the summer and fall of 1996. This was the most frequent topic on the conservative shows and the second most frequent topic on the liberal/moderate shows. While the tenor of the discussion on conservative PTR was certainly more negative, the fact that liberal/moderate PTR gave such prominence to President Clinton's problems may have sent a mixed message. For example, the Don Imus show, although liberal on many issues, often attacked Bill Clinton. In short, there might be less consistency or intensity in political messages among talk show hosts within the conservative or the liberal/moderate PTR groups as compared with the Limbaugh show. And nonlisteners of course get a balanced, less partisan, and-some would say-a diluted message from the mainstream media, diluted, at least, relative to the standards of PTR.

On the other hand, to understand whether exposure or knowledge is the better predictor in the context of attitudes, we tested an additional model that includes both knowledge and exposure in the same equation to see their predictive adequacy. The political knowledge index consisting of eight items and the PTR exposure measure including nonlisteners within each PTR group as a baseline group were put in the same equation. When we added nonlisteners to the exposure scale for each PTR group, we no longer had a single PTR group with ideologically pure exposure, because the nonlisteners would get very different political messages from a single PTR group. Therefore, several other controls, in addition to demographics such as education, political party identification, age, and gender, were employed in the regression equation to equalize the differences between PTR groups and nonlisteners; examples were consumption of mainstream mass media (e.g., the news or editorial sections of a daily newspaper; national TV evening news programs; newsmagazines such as Time, US News, or Newsweek; C-SPAN; programs on National Public Radio such as "Morning Edition" or "All Things Considered"; and "The News Hour" with Jim Lehrer on PBS) and respondent's reported close following of what is going on in public affairs and government.

Comparing exposure and knowledge directly in the same equation reveals an interesting pattern. As Table 3 suggests, we have stronger and more consistent effects of exposure than of knowledge. Most of all, exposure effects are clearly located in the Rush Limbaugh group. All of the exposure effects on Democratic or Republican leaders and their job performance are very strong among the Limbaugh audience. The pattern of 


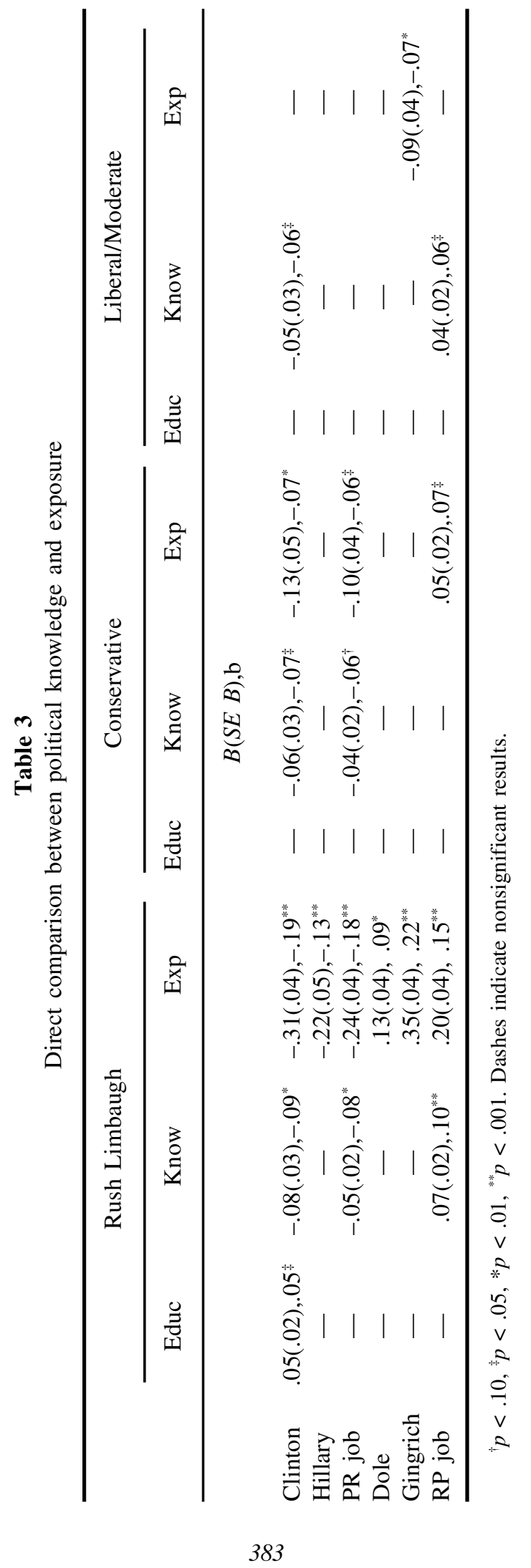


the signs for exposure also shows consistency between reception and favorability. The conservative PTR group also shows some significant effects of exposure on attitudes toward President Clinton, his job performance, and Republican leaders' job performance. There is only one significant effect of exposure-on attitude toward Newt Gingrich among the liberal/moderate audience.

Knowledge has weaker effects across all PTR groups as compared with exposure. For example, among the Rush Limbaugh audience, political knowledge has significant effects only in 3 of 6 cases such as Bill Clinton and his job performance and Republican leaders' job performance. The conservative PTR group shows a significant knowledge effect only on attitude toward President Clinton. The liberal/moderate PTR group shows two significant knowledge effects-on attitude toward Bill Clinton and Newt Gingrichbut the signs of the coefficients are opposite to what we found in the previous analysis with Bill Clinton being rated more negatively but Newt Gingrich more positively at higher levels of political knowledge. ${ }^{12}$ There are no effects of education on attitudes across the PTR groups except on Bill Clinton in the Rush Limbaugh group. In sum, it is important to notice that exposure has the strongest effects in the Rush Limbaugh group, where we could see the strongest effects of both knowledge and exposure on the attitudes among the other PTR groups in each separate equation (Table 1). This implies that the exposure measure works better than the knowledge measure in predicting political attitudes.

\section{Biased Processing}

Listeners in the conservative or the liberal/moderate PTR groups, while skewed toward one party and ideology, are not monolithic. The audiences' political predispositions might bias the way they process messages from the host. Democrats or Independents in the audience of conservative hosts (or Republicans and Independents in the audience for liberal/moderate hosts) could counterargue, selectively attend, selectively recall, or selectively judge the messages that contradict their values.

Tests of biased processing are accomplished by testing the interaction between political party identification and the indicators of reception within each conservative or liberal/moderate PTR group..$^{13}$ Biased processing cannot be tested with the Limbaugh group because there is a large number of conservatives (70\%) and too few liberals $(8.6 \%)$ in his group.

The interaction was tested by examining both the $R^{2}$ change and the standardized coefficient of the interaction effects in a hierarchical regression. Step 1 entered the main effects including political knowledge (or exposure) and party identification. Step 2 entered the interaction between subgroups and knowledge (or exposure). When a significant change in $R^{2}$ was detected, the detailed direction of knowledge (or exposure) on the attitude outcomes under each subgroup was also examined. ${ }^{14}$

Knowledge. At Step 2, there are significant interaction effects between party identification and knowledge on attitudes toward Democratic political leaders within the liberal/ moderate PTR group: Bill Clinton, Hillary Clinton, president's job approval. Republicans and moderates among those listening to liberal/moderate PTR show a positive relationship between knowledge and attitude toward Democratic political leaders: The more knowledge they have, the more favorable they are toward Bill Clinton $(\beta=.133$, $p=.11, n=164)$, Hillary Clinton $(\beta=.214, p=.006, n=162)$, and the president's job performance $(\beta=.173, p=.03, n=151) .{ }^{15}$ The results, however, are contrary to our 
hypotheses. Republicans and Independents have more positive attitudes toward Democratic political leaders as their reception of information increases, while Democrats in this group show no significant relationship between reception and attitudes toward Democratic leaders. The nonsignificant main effects for knowledge on attitudes toward Democratic leaders in Table 1 mask an effect that is due primarily to non-Democrats who are being influenced by the content of this outlet.

The conservative PTR group does not show an interaction between political party and knowledge on attitude toward any political leader except Gingrich. Democrats and Independents among listeners to conservative PTR show a more favorable attitude toward Gingrich as their level of knowledge increases $(\beta=.373, p=.004, n=59)$. Republicans do not show any relationship between knowledge and attitude toward Gingrich $(\beta=.131, p=.26, n=76)$. As before, this effect is contrary to our hypotheses, with those predisposed against the conservative message of the host (non-Republicans) being most likely to accept it if they are knowledgeable.

The curvilinear relationship between political knowledge and attitude toward political leaders was also tested in the subgroup whose underlying predispositions are inconsistent with the hosts' message but consistent with the leaders being evaluated. No quadratic effects were observed.

Exposure. Exposure to PTR also interacts with party identification, but again the results are contrary to our hypotheses. Democrats and Independents who listen to conservative PTR show a significant negative relationship between exposure and attitude toward Clinton and his job performance. The more Democrats and Independents are exposed to conservative PTR, the less favorable they are toward Bill Clinton $(\beta=-.236, p=.037, n=78)$ and his job performance $(\beta=-.200, p=.094, n=71)$. Among Republican listeners to conservative PTR, exposure is unrelated to attitude toward Bill Clinton ( $\beta=.017, p=$ $.895, n=60)$ and his job performance $(\beta=.08, p=.547, n=59)$.

Exposure to PTR shows no relationship to attitudes toward Democratic leaders among Republicans or Independents listening to liberal/moderate PTR.

These results suggest that Democrats and Independents process the information they receive from conservative hosts about Clinton and his job performance differently from Republicans. As exposure increases, they seem to agree more with the hosts' positions, ignoring their own, presumably stable, dispositions. What is especially perplexing is that these results are contrary to our hypotheses but similar in direction to those obtained with knowledge. We expected that audiences with party identifications contrary to those of the host would be less likely to agree with the host's views as exposure (and knowledge) increased and more likely to be biased by their own values. Instead, this group is more likely to agree with the host as reception of information increases. We explore this issue more fully in the final section.

\section{Discussion}

The purpose of our study was to investigate the predictions of Zaller's model of media effects by directly testing the comparative impact of exposure and knowledge as predictors of political attitudes in the context of political talk radio. Political knowledge has been proposed as a better indicator of media reception of political information than exposure (Price \& Zaller, 1993; Zaller, 1992) because knowledge is purported to indicate reception and not just exposure. The concept of exposure has been criticized for many reasons, among them the idea that exposure does not entail attention to information 
or successful reception of information. These assumptions can be fairly interpreted to suggest that the impact of a political source's content on its audience is best indexed by political knowledge.

At the same time, political knowledge reflects not only reception of information but also resistance to being persuaded by that information (Zaller, 1992, 1996). As information on a topic becomes deeper and more connected to other concepts, changing attitudes on the topic becomes more difficult. The upshot of these conflicting trends is the possibility that as knowledge increases, attitudes change in a curvilinear fashion, specifically an inverted $U$ under some circumstances. However, the relationship between knowledge and attitude can take any functional form from positive linear through inverted $U$ to negative linear depending on whether the reception or resistance component dominates (Zaller, 1987).

\section{One-Sided Messages: Limbaugh}

The content of the Rush Limbaugh show is best known and is most clearly one-sided. Its effects on attitudes toward political personalities are also the most well defined. Limbaugh's audiences have attitudes toward Bill Clinton, Mrs. Clinton, Bob Dole, and Newt Gingrich that are consistent with the host's messages favoring Republicans and their leadership and criticizing the president and his wife almost every day. Importantly, as exposure or reception (as knowledge) increases, so does degree of agreement with the Limbaugh message. All of the regression coefficients for both knowledge and exposure are in the predicted direction (12 of 12 comparisons), and 10 of 12 are significant (see Table 1). We found no evidence of curvilinearity in any of the regressions.

Exposure to and reception of Limbaugh's message are associated with the audience's agreement with the direction of the message. This does not mean that Limbaugh's messages cause change. The audience is already predisposed toward being unfavorable toward the president and the first lady and favorable toward Mr. Dole and Mr. Gingrich. Listeners are strongly Republican and conservative to begin with. Nevertheless, these results are consistent with the possibility of Limbaugh's influencing attitudes toward personalities he attacks and supports. The fact that greater reception and exposure are associated with greater agreement is also supportive of possible influence, but obviously not definitive.

The data from the Limbaugh audience provide the clearest test of Zaller's "good variance" argument. Limbaugh's message is clearly one-sided—one-sided against Democratic leaders and one-sided for Republican leaders. In this context, the audience's agreement with the one-sided message is clear and consistent. The data do not support Zaller's operational assumption that knowledge will be a better predictor than exposure or the assumption that persons with moderate knowledge will be most subject to influence.

\section{One-Sided Messages: Conservative and Liberal/Moderate PTR}

The content of conservative and liberal/moderate PTR is not as easily described as that of Limbaugh. Also, the heterogeneity of messages in these two outlets is much greater than for Limbaugh. The consequence is that the impact of messages is less strong and consistent than the impact of exposure to Limbaugh. In our study, the direction of impact was as predicted in 19 of 24 comparisons (11 in conservative PTR and 8 in liberal/moderate PTR; see Table 1). Of the 19 effects in the predicted direction, 4 were statistically significant. None of the regression coefficients in the unpredicted direction is significant. 
Despite the heterogeneity of content, the overall pattern of effects for conservative and liberal/moderate PTR on attitudes toward political leaders is consistent with the stronger effects found for Rush Limbaugh. The most important effects for exposure to conservative PTR concern Bill Clinton and his job performance. Those who listen more to the conservative PTR were less positive toward Bill Clinton and the president's job performance. People listening to liberal/moderate PTR tended to have more positive attitudes toward Hillary Clinton and more negative attitudes toward Newt Gingrich. Attitudes toward President Clinton and his performance ratings were unrelated to exposure to liberal/moderate PTR, perhaps reflecting the hosts' willingness to criticize the president and his behavior despite otherwise liberal leanings.

Overall, there appears to be a relationship between the content of liberal/moderate and conservative PTR and their audiences' attitudes toward political leaders. The effects are not strong ones, but, given the heterogeneity of these outlets, this is not surprising. No evidence of a nonlinear relationship was uncovered.

\section{Knowledge Versus Exposure}

We found no evidence of quadratic effects when knowledge is used to predict attitudes toward political leaders of either party. Therefore, all of the direct comparisons between knowledge and exposure to PTR as predictors of political attitudes are linear ones. Knowledge and exposure agree with one another in sign in 5 of 18 comparisons after controls for demographics. Exposure is a significant predictor of political attitude (10 of 18) more frequently than knowledge is (4 of 18). The two agree in both significance and direction 4 of 18 times (see Table 1). The correlation between the betas for knowledge and exposure on outcomes is $.84(n=18)$.

\section{Biased Processing}

The effects of audience biases in processing partisan messages from PTR were also investigated in two ways. Although the audience of PTR tends to be highly self-selected, drawing people who are already disposed toward agreeing with the hosts' positions, it is still not monolithic. In particular, the audiences of conservative and liberal/ moderate PTR include enough nonpartisans and those of an opposite ideology to investigate their reactions to contrary messages. The audience of Rush Limbaugh is too Republican and conservative to study the reactions of Democrats and Independents.

We hypothesized that listeners whose political ideologies diverge from that of the host would tend to reject messages opposed to their a priori party identifications, being less affected by criticisms directed at those the listeners favor and less affected by praise for those the listeners oppose. No evidence to support these hypotheses was found for exposure or knowledge. In fact, the only significant effects were contrary to our hypotheses. Although the results are neither strong nor consistent, they are intriguing and deserve scrutiny.

Republicans and Independents who listen to liberal/moderate PTR had more positive attitudes toward Bill Clinton, Hillary Clinton, and the president's performance with increasing knowledge than did Democrats listening to the same sources. Democrats and Independents listening to conservative PTR had more positive attitudes toward Newt Gingrich as knowledge increased than Republicans did. Democrats and Independents listening to conservative PTR had more negative attitudes toward Bill Clinton with increasing exposure than Republicans did. 
Several possible explanations of these results should be explored. These include (a) ceiling effects for those who are already disposed toward the sources' positions and (b) differences between partisans who listen to ideologically contrary programming and partisans who either do not listen or select ideologically similar programming. Ceiling effects would exist if, for example, Republicans who listen regularly to conservative PTR have more extreme attitudes toward Democrat and Republican leaders than Republicans who do not listen at all or who listen to liberal/moderate PTR. In effect, this comparison group would have less variation in their attitudes regardless of exposure or knowledge levels and, hence, weaker associations to knowledge or exposure. The second possibility implies, for example, that the very act of a Republican choosing to listen to liberal/moderate PTR indicates the person is less committed, more ideologically complex, or more conflicted about his or her reported party identification than, say, a person choosing only to listen to conservative outlets.

There is no strong evidence of ceiling effects. Although Democrats and Independents have more favorable attitudes toward the Clintons and the president's job performance than do Republicans and Independents for all listening groups, the highest mean is 3.76 (on a 5-point scale) for those listening to liberal/moderate PTR. The other means for the group of Democrats and Independents range from 2.82 to 3.61. For Republicans and Independents, their attitudes toward Republican leaders are more favorable than Democrats and Independents for all listening groups. However, the highest mean is 3.56 (on a 5-point scale) for Republicans and Independents listening to conservative PTR. The other means range from 2.27 to 3.54 . Restricted variance from ceiling effects cannot explain the results of the biased processing analyses.

To evaluate the possibility that Republicans and Independents who listen to liberal/ moderate PTR are different from other Republican and Independent groups (and similarly for Democrats and Independents who listen to conservative PTR), we considered liberal-conservative self-identifications by the respondents in each group. The results of this analysis are presented in Table 4. They confirm that those choosing to listen to ideologically contrary programming are less ideologically extreme. The most ideologically extreme groups are those listening to PTR that is consistent with their ideologies. For example, Republicans and Independents listening to conservative PTR identify themselves as most conservative (mean $=3.72$ on a 5 -point scale). Especially interesting

\section{Table 4}

Listeners' self-reported political ideology

( 1 = very liberal, 5 = very conservative $)$ : Partisan groups by PTR listeners

\begin{tabular}{lccc}
\hline PTR group & $\begin{array}{c}\text { Nonlistener } \\
{[\text { mean }(S D)]}\end{array}$ & $\begin{array}{c}\text { Conservative } \\
\text { PTR } \\
{[\text { mean }(S D)]}\end{array}$ & $\begin{array}{c}\text { Liberal/moderate } \\
\text { PTR } \\
{[\text { mean }(S D)]}\end{array}$ \\
\hline Dem/Inds & $\begin{array}{c}2.97(0.89) \\
(N=709)\end{array}$ & $\begin{array}{c}3.08(0.89) \\
(N=77)\end{array}$ & $\begin{array}{c}2.78(0.86) \\
(N=222)\end{array}$ \\
$F(2,1008)=5.16, p=.006$ & $3.29(0.88)$ & $3.72(0.88)$ & $3.07(0.84)$ \\
Rep/Inds & $(N=624)$ & $(N=102)$ & $(N=161)$ \\
$F(2,887)=16.88, p<.000$ & & &
\end{tabular}


is the comparison between Democrats and Independents listening to conservative PTR and Republicans and Independents listening to liberal/moderate PTR. Their average reported ideology is identical and very near the midpoint of the scale (3.07 and 3.08, respectively).

The results suggest that the listeners of ideologically contrary PTR do not conform to the ideological and partisan dispositions of those who self-select ideologically similar programming. They may very well be ready to receive rather than resist ideologically counter messages. The behavior of choosing a host and program that counters their avowed partisan predispositions is likely more important information about their real values than their stated political party affiliation or leaning. Thus, some biased processing is present, but partisanship did not indicate the direction of the bias, while choice of programming outlet did. For example, the Republicans and Independents who listen to liberal/moderate PTR may be cognitively quite different from the Republicans and Independents in other subgroups, perhaps being more ideologically complex or conflicted. Perhaps, instead of reacting against the messages of the contrary host because of their partisan predispositions, they tend to agree with the host as reception increases because their full set of predispositions are not fundamentally opposed to the contrary messages. In short, the biased processing hypotheses may still be tenable because simple measures of being Republican and Democrat are insufficient to capture bias. Behavioral action in the form of selecting a source that is ideologically different may be a better indicator of what the real disposition of the audience is.

In sum, our test of the biased processing component of Zaller's theory within the audiences of conservative and liberal/moderate PTR was not successful. Where there was evidence of an interaction between political party identification and PTR group, the direction was counter to our hypotheses. However, the reason for this failure may be due more to the pre-dispositions of that group of Republicans and Independents who are willing to listen to liberal/moderate PTR: They may be more open and susceptible to influence from the left or more ideologically complex and conflicted about their partisanship. Whatever the reason, this group's bias was toward increasing agreement with the host's message as reception increased.

\section{Summary}

The data reported in this article are consistent with three conclusions about Zaller's model as applied to PTR. First, when an audience is exposed to an intense, one-sided message, their agreement with the positions advocated increases as exposure and reception increase. This was true of the Limbaugh audience in the study and is consistent with Zaller's claims about the effects of communication when messages are one-sided. Second, exposure is as good a predictor of reception as knowledge when exposure is carefully measured and the outcome is a political attitude rather than political knowledge. This claim is contrary to Zaller's assumptions about the efficacy of political knowledge as the better indicator of the effects of habitual news reception. Third, the standard indicators of biased processing (e.g., Republicans listening to liberal/moderate PTR) may not be useful when the audience can select among partisan sources. We found evidence that the audience's partisan predispositions readied them for agreement with the host, rather than resistance. In the context of this study, the act of choosing to listen to a host whose ideology is counter to one's stated party identification may be more indicative of value predispositions than the symbolism of party. 


\section{Notes}

1. Bartels (1993) finds that the ordinary least squares estimates generally understate the effects of television news and newspaper exposure, in some cases by as much as $50 \%$, while overstating the impact of party identification on opinion change and, most dramatically, understating the persistence of prior opinions (p. 271). Although this is a useful solution in some contexts, it does not work in general. For example, errors-in-the-variables corrections have not been solved for the case of models with interaction effects.

2. Ten items of general political knowledge can be divided into two broad areas: civics knowledge and knowledge about political figures. Civics knowledge includes the questions "which party is more conservative?" and "Which party controls the House of Representatives and the U.S. Senate?" Knowledge about political figures includes questions about the political offices held by figures such as Ted Kennedy, George Schultz, William Rehnquist, Mikhail Gorbachev, Margaret Thatcher, and Yasser Arafat, and identification of the name of at least one congressional candidate running in the respondent's district.

3. For each of the 16 stories, in fact, the measure of political knowledge was the one most strongly related to recall, reducing classification errors by nearly one half $(46 \%)$ and producing coefficients generally two or three times larger than those obtained for education, media exposure, or political discussion.

4. These results conflict with previous findings from survey research on learning from the media. Previous findings indicate that newspaper reading and interpersonal discussion show stronger relationships with learning of the news than does television viewing (for a review, see Robinson \& Levy, 1986). However, Robinson and Levy used outcome measures of learning that included issues not currently being covered by media outlets and employed straight exposure as the measure of news reception. Price and Zaller's (1993) topics were more current.

5. The surveys were conducted by Princeton Survey Research Associates (1997) for the Annenberg School for Communication at the University of Pennsylvania. The sample was an RDD sample of the population with an oversample for regular listeners. The base sample had a response rate of $38.5 \%$ (response rate 1 according to the American Association of Public Opinion Research) and a cooperation rate of $62.6 \%$ (cooperation rate 1 according to the American Association of Public Opinion Research).

6. The listeners to liberal/moderate PTR were $51.1 \%$ moderates, $29.4 \%$ liberals, $39 \%$ Independents, and $43.1 \%$ Democrats. Nonregular listeners were $32.4 \%$ conservatives, $44.2 \%$ moderates, $23.3 \%$ liberals, 26.3\% Republicans, 38.1\% Independents, and 35.6\% Democrats.

7. Respondents' civics knowledge was measured by two questions: "How much of the vote is needed in both the U.S. Senate and House to override a Presidential veto?" (50\%, 60\%, 2/3, 3/ $4, \mathrm{DK})$ and "Which political party has a majority in the United States House of Representatives? (Republicans, Democrats, DK). Incorrect and "DK" responses were coded as incorrect (=0).

Current knowledge of social affairs was measured with two questions: "What is your best estimate of the number of people convicted of murder who are actually executed in the United States each year?" $(300,100,50$, less than $10, \mathrm{DK})$ and "What is your best estimate of how many welfare recipients have been on welfare three years in a row or more?" $(10 \%, 30 \%, 50 \%, 75 \%$, DK).

News knowledge was measured by two questions: "In Bosnia, do you know how much of the NATO peacekeeping forces U.S. troops will make up?" (most, about half, less than half, DK) and "Do you know the tax rate Presidential Candidate Steve Forbes is discussing?" (10\%, 17\%, $24 \%, 31 \%$, DK).

Respondents' recognition of political figures was also included in the measurement of political knowledge: Pat Buchanan, Steve Forbes, Lamar Alexander, Bill Bennett, and Rush Limbaugh. Zaller also used recognition of political figures as a part of his knowledge measures. If respondents could rate each of the figures, they were presumed to know who the political figure is. Thus, those who rated a political figure on the evaluative horizon of "very favorable" to "very unfavorable" were coded as " 1 "; those who "never heard of" were coded as " 0 ."

DK or refusal rates for the six knowledge items were as follows: the percentage of vote for 
overriding a presidential veto, $21.2 \%$; majority party in the House of Representatives, $17.2 \%$; the percentage of U.S. troops in the Bosnia peacekeeping force, 21.1\%; Steve Forbes's tax rate, 29.2\%; the number of people executed each year, $7.9 \%$; and the number of people on welfare three years in a row or more, $4.7 \%$. The rates of answering "never heard of" for each political figure were: Pat Buchanan, 2.9\%; Steve Forbes, 9.8\%; Lamar Alexander, 21.8\%; Bill Bennett, 48.2\%; and Rush Limbaugh, 3.8\%.

8. According to Delli Carpini and Keeter (1991, 1992, 1993, 1996), the structure of people's political knowledge is fundamentally unidimensional so that measures of national political knowledge in one domain can provide reasonably good measures of overall knowledge about national politics. They also argue that political knowledge is very stable and that short scales can measure political knowledge effectively.

9. Political party identification was measured with the following scale: "strong Democrat" (1), "Democrat" (2), "Independent" (3), "Republican" (4), and "strong Republican" (5).

10. Based on concern that our political knowledge measure is more a measure of respondents' opinionation than of factual knowledge, we ran the same series of regressions among the PTR groups using the measure of six factual political knowledge items while excluding the five items of respondents' recognition of political figures. Using only six items produced lower reliability (Cronbach's alpha $=.41$ ). However, we found that the factual knowledge measure produced about the same results as the more reliable measure.

11. This scale was created by multiplying dummy variables of each PTR group in the first step by political knowledge score (or exposure level).

12. We suspected that knowledge has weaker effects than exposure because education in the equation picked up some knowledge effects. Therefore, we ran the regression again with only education deleted from the controls. This produced about the same results across all of the PTR groups as the regression with education included in the controls. In this analysis, knowledge effects increased somewhat but did not become significant.

13. To test interaction effects, the conservative and liberal/moderate PTR groups were subdivided into two subgroups according to party identification. Within the conservative PTR group (total = 138), "strong Democrats (20)," "Democrats (15)," and "neither/both (43)" were combined into one subgroup (subtotal $=78$ ), while "Republicans (22)" and "strong Republicans (38)" were combined into the other ( subtotal $=60$ ). Within the liberal/moderate PTR group (total $=280$ ), "strong Republicans (21)," "Republicans (27)," and "neither/both (116)" were placed in one subgroup (subtotal = 164), while "strong Democrats (64)" and "Democrats (52)" were placed in the other (subtotal $=116)$. Dummy variables within each PTR group were created. The conservative PTR group has two dummy variables such as Republicans (1) and Democrats/moderates (or Independents) (0), and the liberal/moderate group also has two dummy variables such as Democrats (1) and Republicans/moderates (or Independents) (0). The interaction term is created by multiplying dummy variables of each PTR group by political knowledge scores or exposure levels at Wave 1.

14. This was done first by selecting the individual cases of each subgroup, second by running the regression for the attitude outcomes on knowledge, and third by examining the direction of the interaction coefficients.

15. However, Democrats among that PTR group do not show any relationship between knowledge and attitudes or job approvals. We did not find the opposite (negative) influence of political knowledge on attitudes toward Republican leaders among Democrats within the liberal/moderate PTR group, either.

\section{References}

Armstrong, C. B., \& Rubin, A. (1989). Talk radio as interpersonal communication. Journal of Communication, 39(2), 84-94.

Barker, D. (1996, March). Rush to action: Political talk radio and health care reform. Paper presented at the meeting of the Southwest Political Science Association, Houston, TX. 
Bartels, L. (1993). Message received: The political impact of media exposure. American Political Science Review, 87, 267-285.

Berelson, B., Lazarsfeld, P., \& McPhee, W. (1954). Voting: A study of opinion formation in a presidential campaign. Chicago: University of Chicago Press.

Bick, J. (1988). [Review of Talk radio and the American dream]. Journal of Broadcasting \& Electronic Media, 32, 121-122.

Bierig, J., \& Dimmick, J. (1979). The late night radio talk show as interpersonal communication. Journalism Quarterly, 56, 92-96.

Boyer, P. (1992). Bull rush. Vanity Fair, 55, 156-160.

Cappella, J. N., \& Jamieson, K. H. (1997). Spiral of cynicism: The press and the public good. New York: Oxford University Press

Cappella, J. N., Jamieson, K. H., \& Turow, J. (Eds.). (1996). Call-in political talk radio: Background, content, audiences, portrayal in mainstream media. Philadelphia: University of Pennsylvania, Annenberg Public Policy Center.

Chaffee, S., \& Schleuder, J. (1986). Measurement of effects of attention to media news. Human Communication Research, 13, 76-107.

Crittenden, J. (1971). Democratic functions of the open mike radio forum. Public Opinion Quarterly, 35, 200-210.

Delli Carpini, M. X., \& Keeter, S. (1991). Stability and change in the U.S. public's knowledge of politics. Public Opinion Quarterly, 55, 583-612.

Delli Carpini, M. X., \& Keeter, S. (1992). The public's knowledge of politics. In J. D. Kennamer (Ed.), Public opinion, the press, and public policy. Westport, CT: Praeger.

Delli Carpini, M. X., \& Keeter, S. (1993). Measuring political knowledge: Putting first things first. American Journal of Political Science, 37, 1179-1206.

Delli Carpini, M. X., \& Keeter, S. (1996). What Americans know about politics and why it matters. New Haven, CT: Yale University Press.

Drew, D., \& Weaver, D. (1990). Media attention, media exposure, and media effects. Journalism Quarterly, 67, 740-748.

Herbst, S. (1995). On electronic public space: Talk shows in theoretical perspective. Political Communication, 12, 263-274.

Hoffstetter, C. R., Donovan, M. C., Klauber, M. R., Cole, A., Huie, C. J., \& Yuasa, T. (1994). Political talk radio: A stereotype reconsidered. Political Research Quarterly, 47, 467-479.

Hovland, C. I., Janis, I. L., \& Kelley, H. H. (1953). Communication and persuasion: Psychological studies of opinion change. New Haven, CT: Yale University Press.

Inamdar, U., \& Cappella, J. N. (1997). The 1996 general election: Topical coverage of presidential candidates and campaign issues by the Rush Limbaugh Show (with comparisons to other media). Unpublished report, Annenberg School for Communication, University of Pennsylvania, Philadelphia.

Jamieson, K. H., Cappella, J. N., \& Turow, J. (1998). Rush Limbaugh: The fusion of party leader and partisan mass medium. Unpublished report, Annenberg School for Communication, University of Pennsylvania, Philadelphia.

Joslyn, M. R., \& Ceccoli, S. (1996). Attentiveness to television news and opinion change in the fall 1992 presidential campaign. Political Behavior, 18, 141-170.

Klapper, J. (1960). The effects of mass communication. Glencoe, IL: Free Press.

Knight, K., \& Barker, D. (1996, September). Talk radio turns the tide? The Limbaugh effect: 1993-1995. Paper presented at the meeting of the American Political Science Association, San Francisco.

Krosnick, J. A., \& Brannon, L. A. (1993). The impact of the Gulf War on the ingredients of presidential evaluations: Multidimensional effects of political involvement. American Political Science Review, 87, 963-975.

McGuire, W. (1986). The myth of massive media impact: Savagings and salvagings. Public Communication and Behavior, 1, 173-257. 
McLeod, J. M., \& McDonald, D. G. (1985). Beyond simple exposure: Media orientations and their impact on political process. Communication Research, 12, 3-33.

Page, B., \& Tannenbaum, J. (1996). Populistic deliberation and talk radio. Journal of Communication, 46(2), 33-54.

Petrozzello, D. (1994, October 17). Hundt to radio show: Truth in broadcasting. Broadcasting and Cable, p. 11.

Price, V., \& Czilli, E. (1996). Modeling patterns of news recognition and recall. Journal of Communication, 46(2), 55-78.

Price, V., \& Zaller, J. (1993). Who gets the news: Alternate measures of news reception and their implications for research. Public Opinion Quarterly, 57, 133-164.

Princeton Survey Research Associates. (1997). Political talk radio: Methodological report. Princeton, NJ: Author.

Rahn, W. M., Krosnick, J. A., \& Breuning, M. (1994). Rationalization and derivation process in survey studies of political candidate evaluation. American Journal of Political Science, 38, $582-600$.

Robinson, J. P., \& Levy, M. R. (1986). The main source: Learning from television news. Beverly Hills, CA: Sage.

Sears, D. O., \& Kosterman, R. (1994). Mass media and political persuasion. In S. Shavitt \& T. C. Brock (Eds.), Persuasion: Psychological insights and perspectives (pp. 251-278). Needham Heights, MA: Allyn \& Bacon.

Sniderman, P., Brody, R., \& Tetlock, P. (1991). Reasoning and choice: Explorations in political psychology. New York: Cambridge University Press.

Surlin, S. (1986). Uses of Jamaican talk radio. Journal of Broadcasting \& Electronic Media, 30, $459-466$.

Turow, J. (1974). Talk show radio as interpersonal communication. Journal of Broadcasting, 18, $171-179$.

Zaller, J. (1987). The diffusion of political attitudes. Journal of Personality and Social Psychology, 53, 821-833.

Zaller, J. (1992). The nature and origins of mass opinion. New York: Cambridge University Press.

Zaller, J. (1994). Elite leadership of mass opinion: New evidence from the Gulf War. In L. Bennett \& D. Paletz (Eds.), Taken by storm (pp. 186-209). Chicago: University of Chicago Press.

Zaller, J. (1996). The myth of massive media impact revived. In D.C. Mutz, P. M. Sniderman, \& R. A. Brody (Eds.), Political persuasion and attitude change (pp. 17-78). Ann Arbor: University of Michigan Press.

Zaller, J., \& Hunt, M. (1995). The rise and fall of candidate Perot: The outsider vs. the systemPart II. Political Communication, 12, 97-123.

\section{Appendix}

In order to determine who was and was not a listener to political talk radio, a series of screening questions was asked. These included (a) a definition of political talk radio ("I'd like to ask you about some political talk radio shows, where listeners call in to discuss politics and public affairs"); (b) a question about whether the respondent ever listened to PTR; (c) a question about regular listening including the alternatives regularly, sometimes, hardly ever, or never; and (d) a question about the frequency with which the respondent listens: "On the average, how often do you listen to [this] talk radio show-less than once a week, once a week, twice a week, 3 times, or more than 3 times a week?" People were queried about listening to Rush Limbaugh and to other hosts. Interviewers asked the hosts' names. 
The "multiple listeners" group (4\%) comprised those listening to Limbaugh and (at least) one other show regularly ( 2 or more times per week). This potentially interesting group was not followed because we wanted to study the Limbaugh audience unaffected as much as possible by the influence of other hosts and because of its small size.

The group designated as "other" regular listeners to PTR $(N=422)$ was subdivided into those listening regularly to the liberal/moderate $(N=283)$ or the conservative shows $(N=139)$. These two subgroups were determined on the basis of the listener's assessment of the host's political views as liberal, moderate (in between, neither conservative nor liberal, both conservative and liberal), or conservative.

Of regular listeners to PTR other than Limbaugh, a small number indicated they listened to two $(N=53)$ or more $(N=13)$ PTR shows at least twice per week. Of these 66, 26 listen to ideologically similar shows as their first and second choices; 26 more listen to ideological neighbors (moderate to conservative or liberal to moderate, etc.) as their second choice. In all cases, respondents were assigned to conservative or liberal/ moderate listening groups based on the show they named first.

Respondents were assigned to listening groups on the basis of their identification of the host's political views as liberal, conservative, or moderate. The groups could have been determined in two other ways. One alternative was the name of the show or its host along with its avowed, and often published, political orientation. The second was listeners' own political ideology in combination with their assessment of the degree of similarity or dissimilarity with the host's views. The groups created by the three methods were all very similar, and results indicated little difference in findings regardless of which method was used to establish the groupings. The most direct method was used, thereby preserving the most observations.

Although it would have been useful to separate the liberal and moderate PTR groups, the number of regular listeners identifying their host's views as liberal was too small $(N=86)$ to permit a separate group. 